LA-7885-MS, Vol. VII

Informal Report

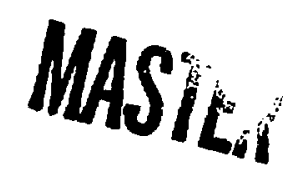

\title{
1-GWh Diurnal Load-Leveling Superconducting Magnetic Energy Storage System Reference Design
} Appendi: F: 1-GWh Electrical System Design 
LA-7885-MS, Vol. VII

Informal Report

UC-20b and UC-94b

Issued: September 1979

\section{1-GWh Diurnal Load-Leveling Superconducting Magnetic Energy Storage System Reference Design}

Appendix F: 1-GWh Electrical System Design

H. J. Boenig

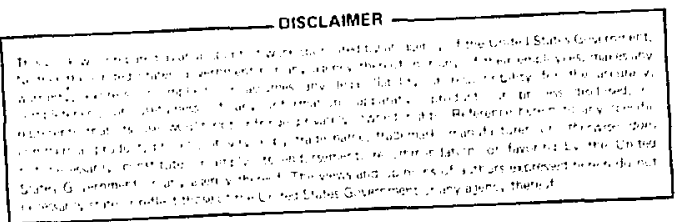


1-GWh DIURNAL LOAD-LEVELING SUPERCONDUCTING MAGNETIC ENERGY STORAGE SYSTEM REFERENCE DESIGN

APPENDIX F

1-GWh ELECTRICAL SYSTEM DESIGN

by

H. J. Boenig

\begin{abstract}
Two circuit configurations for reducing the installed converter power and cost of high-power converter systems that operate in a cunstant power mode over a wide current and voltage range are suggested and analyzed.
\end{abstract}

\title{
I. INTRODUCTION
}

Different technological processes such as glass melting, silicon decomposing, plasma generation, and storing of energy in superconducting magnets require high-power dc supplies with constant output power over a wide voltage and current range. Line-commutated thyristorized converters are generally used for these applications. They provide, by proper gate control of the thyristors, a variable output voltage and, if necessary, two-directional power flow. The required voltage standoff capability of the converter and the very restricted thermal overload characteristic of the thyristors force the designer to size the converter according to the maximum voltage and maximum current, although in a constant-power mode of operation these two parameters do not occur simultaneously.

A power supply with constant-power output operatinc over a wide current and voltage range would be largely overdesigned when sized according to maximum current and voltage values. The converter utilization, u, defined as the ratio of constant output power $P_{0}$ to installed converter power $P_{C}$, 


$$
\mathrm{u}=\frac{\mathrm{P}_{\mathrm{o}}}{\mathrm{P}_{\mathrm{c}}},
$$

should be as close to unity as possible to guarantee low converter cost. Constant-power output over a current to voltage ratio, defined as

$$
\varepsilon=\frac{I_{\max }}{I_{\min }}=\frac{V_{\max }}{V_{\min }},
$$

is shown in Fig. F-I for a specific supply where $\varepsilon=4$. Point A represents a converter design according to $V_{\max }$ and $I_{\max }$; and the utilization of that converter is 0.25 .

Currently, circuits such as manual series-parallel bridge switching ${ }^{l}$ or autotap changing ${ }^{2}$ are being employed to reduce the installed converter power without limiting the constant-power mode of operation over the full current and voltage range.

Some basic guidelines are presented in this appendix for two converter schemes that have great potential of being implemented for the constant-power mode of operation because they reduce the installed converter power and are suitable for a two-quadrant converter operation. The module by-pass scheme uses a series connection of converter modules, each designed for a different voltage and current rating. Each module can be by-passed when the module rating is exceeded to adjust for the constant output power over the full current-voltage range. An optimization procedure is given to determine the current and voltage rating of the converter modules for the lowest installed converter power. The circuit for a novel series-parallel module switching scheme is examined. This circuit allows converter bridges to be switched from a series connection in the high-voltage, low-current mode to a parallel connection when low voltages and high currents are requirèd. Switching occurs without load current interruption in both rectifier and inverter mode of the dc supply. 
For both schemes, an expression for the installed power of the dc supply has been derived as a function of $\varepsilon$. The reactive-power requirement for both clrcults has also been evaluated. Depending on the current or voltage ratio, the scheme with the lowest installed converter power is determined.

\section{MODULE BY-PASS SWITCHING}

For the following discussion, a dc supply is assumed to consist of converter modules, each of which can be a 6- or 12-pulse bridge along with their transformers or a number of such units in parallel and/or in series. In the module or bridge by-pass switching scheme, a high-power converter is subdivided into several modules connected in serles. The total voltage rating of all series-connected modules equals the maximum converter voltage. Each module is designed for a different current rating and can be by massed by a switch. At a given load current, those modules are by-passed whose current rating is smaliex than the load current. Figure F-2 shows a converter consisting of three modules. Module 1 is designed for maximum load current, module 2 for a smaller load current, and module 3 for an even smaller current. Figure F-3 demonstrates the rating of the individual converter modules in the voltage-current plane. Each module can be designed for an equal voltage rating. However, it will be shown below that for a given number of nodules, $n$, a different voltage rating for each module gives the lowest installed converter power.

\section{A. Optimization Procedure}

The total installed converter power, $P_{c}$, which/is the sum of the installed power of all $\mathrm{n}$ modules, is given by the equation

$$
P_{c}=\sum_{r}^{n} V_{r} I_{r}
$$

with $r$ as the running module number. $V_{r}$ and $I_{r}$ are the rated voltage and current of the r-th module. This power rating must be minimized. For a general derivation, per-unit values are introduced. With $P_{0}$ as the power base, the installed converter power becomes 


$$
\mathrm{P}_{\mathrm{c}}=\frac{\mathrm{P}_{\mathrm{c}}}{\mathrm{P}_{\mathrm{o}}}=\frac{1}{\mathrm{u}} \text {. }
$$

(In the text, lower case letters are used for per-unit notation, and upper case letters denote physical variables.) The following boundary concitions must be met.

1. The sum of all module voltages must be equal to the required maximum converter voltage, $V$. This leads to the condition

$$
v=\sum_{x}^{n} v_{r}
$$

or on a per-unit basis with $\mathrm{V}$ as the base,

$$
\frac{\sum^{n} v_{r} v_{r}}{v}=\sum_{r} v_{r}
$$

2. The current rating of the first module must be equal to the maximum converter current

$$
I_{1}=I
$$

This condition can be reqritten on a per-unit basis with $I$ as the current base as

$$
\frac{I_{1}}{I}=I_{1}=1
$$

3. The condition that the q-th converter module is by-passed when its current rating, $I_{q}$, is exceeded by the load current can be formulated by the equation 


$$
I_{q}=\frac{P_{o}}{q-1},
$$

for $q>1$. The last equation can be written on a per-unit basis as

$$
I_{q}=\frac{I_{q}}{I}=\frac{1}{q-1}
$$

Inserting the expression for $P_{0}$ as obtained from $\mathrm{Eq} \cdot(\mathrm{F}-9)$ into $\mathrm{Eq} \cdot(\mathrm{F}-4)$ and using the boundary condition of Eq. $(F-7)$ results in a per-unit installed converter power in the expanded form given by

$$
\begin{aligned}
& p_{c}=\varepsilon v_{1}+\frac{v_{2}}{v_{1}}+\frac{v_{3}}{v_{1}+v_{2}}+\ldots \ldots \ldots+\frac{v_{n_{1}}}{n-1} . \\
& \mathrm{r} \stackrel{\sum}{=} \mathrm{v}_{\mathrm{r}}
\end{aligned}
$$

As Eq. $(F-11)$ shows, the installed converter power is a function of the voltage rating of each module. To minimize $\mathrm{p}_{\mathrm{c}}$, Eq. $(\mathrm{F}-11)$ must be differentiated with respect to the unknown, $v_{r}$, and the partial derivatives, $\partial p_{c} / \partial v_{r}$, must be set equal to zero. This gives ( -1 ) equations to determine the optimum voltage value of each converter for the arbitrary module division $n$.

\section{B. Example}

To show the optimization procedure, a converter design is assumed for constant-power operation over a current-voltage range of $\varepsilon=4$.

1. One converter module. Equation $(F-11)$ with $n=1$ yields

$$
\mathrm{P}_{\mathrm{c}, \mathrm{n}}=1=\varepsilon \mathrm{v}_{1} \text {. }
$$


The total converter power is 4 per unit for $v_{1}=1$. The converter utilization is $25 \%$.

2. Two converter modises. Equation $(F-1)$. where $n=2$ and the relationship $v_{1}+v_{2}=1$ results in

$$
P_{c, n}=2=\epsilon v_{1}+\frac{1}{v_{1}}-1 \text {. }
$$

The differentiation of the above equation with respect to $v_{1}$ yields

$$
\frac{\partial P_{c}}{\partial v_{1}}=\epsilon-\frac{1}{v_{1}^{2}}
$$

By setting the last equation equal to zero, the optimum voltage rating for $v_{1}$ is

$$
v_{1}=\varepsilon^{-1 / 2}
$$

The total. finsi:lited converter power has been reduced to

$$
p_{C, n=2}=2 \varepsilon^{1 / 2}-1,
$$

which is equal to 3 for $\varepsilon=4$. This is a $25 \%$ reduction in installed converter power compared to case 1 .

3. Three converter modules. Using Eqs. $(F-6)$ and $(F-11)$ with $n=3$ results in

$$
P_{c, n}=3=\varepsilon v_{1}+\frac{v_{2}}{v_{1}}+\frac{1}{v_{1}+v_{2}}-1 \text {. }
$$


The partial derivatives with respect to $v_{1}$ and $v_{2}$ set equal to zero result in the two equations

$$
\varepsilon-\frac{v_{2}}{v_{1}^{2}}-\frac{1}{\left(v_{1}+v_{2}\right)^{2}}=0 \text {, }
$$

and

$$
\frac{1}{v_{1}}-\frac{1}{\left(v_{1}+v_{2}\right)^{2}}=0 \text {. }
$$

From the last equation it follows that

$$
v_{2}=\left(v_{1}\right)^{1 / 2}-v_{1}
$$

Voltage $v_{2}$ is a positive number because $v_{1}$ is less than unity. Combining Eqs. $(F-18)$ and $(F-20)$ yields as optimum module voltage ratings

$$
v_{1}=\varepsilon^{-2 / 3}
$$

and

$$
v_{2}=\varepsilon^{-1 / 3}-v_{1}
$$

The installed coverter power can now be calculated by inserting Eqs. $(F-21)$ and $(\mathrm{F}-22)$ into $\mathrm{Eq} \cdot(\mathrm{F}-17)$ to obtain

$$
\mathrm{p}_{\mathrm{c}, \mathrm{n}}=3=3 \varepsilon^{1 / 3}-2
$$


Here $p_{c}$ is equal to 2.762 for $\varepsilon=4$, which is another $10 \%$ reduction as compared to case 2 .

of academic interest is the case in which $n$ equals infinity. From Fig. F-1, the conclusion is that the installed coverted power is proportional to the area under the constant-power curve, given as

$$
P_{c, n=\infty}=V I_{\min }+\int_{I_{\min }}^{I_{\max }} \frac{P_{o}}{I} d I
$$

and

$$
\mathrm{P}_{\mathrm{c} ; \mathrm{n}}=\infty=\mathrm{P}_{\mathrm{O}}(1+\ln \varepsilon)
$$

The result can be written on a per-unit basis as

$$
\mathrm{p}_{\mathrm{c}, \mathrm{n}=\infty}=1+\ln \varepsilon
$$

With $\varepsilon$ equal to 4 , the installed converter power for a large number of modules would approach the value $\mathrm{p}_{\mathrm{C}}=2.39$. Comparison of the amount of installed converter power for different $n$ values shows that most of the posstble reduction in $p_{c}$ has been obtained for $n$ equal to 3 . The saving in converter rating decreases rapidly as $n$ increases further. In the module-switching scheme, the installed converter power always exceeds $1+\ln \varepsilon$ and the converter utilization approaches the value

$$
\mathrm{u}=\frac{1}{1+\ln \varepsilon}
$$

Table F-I contains the numerical values of the optimum module voltages for different module numbers $n$ and current-voltage ratios $\varepsilon$. 
OPTIMUM MODULE VOLTAGES FOR DIFFERENT MODULE NUMBERS AND CURRENT-VOLTAGE RATIOS


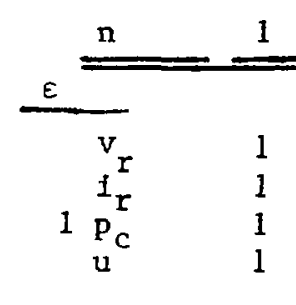

$\begin{array}{lllllllll}v_{r} & 1 & 0.71 & & 0.29 & 0.63 & 0.17 & 0.20 & \\ i_{r} & 1 & 1.0 & & 0.71 & 1.0 & 0.79 & 0.63 & \\ v_{c} & 2 & & 1.83 & & & 1.77 & & 1.69 \\ \mathrm{u} & 0.5 & & 0.55 & & & 0.56 & & 0.59\end{array}$

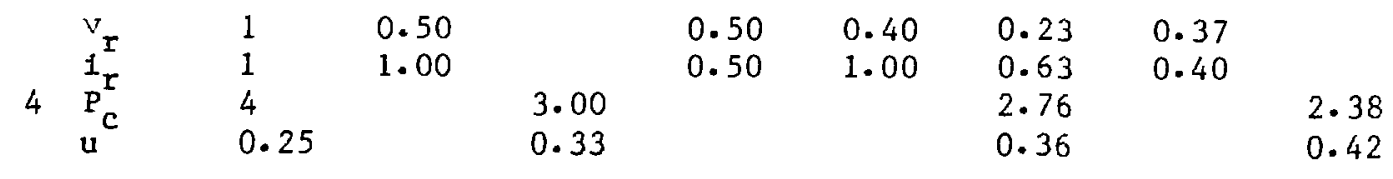

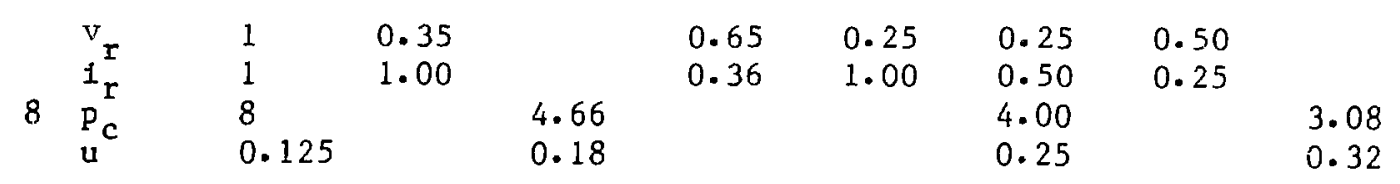

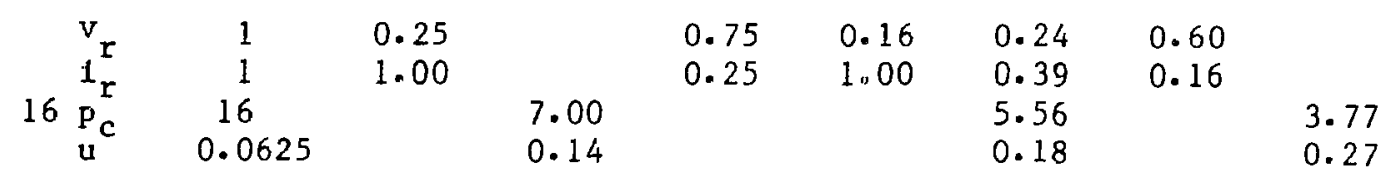

\section{Reactive Power Requirements}

Line-commutated converters, which operate in both the rectifier and the inverter mode, require reactive power. Reactive power compensation equipment

5 must be installed to improve the power factor. A design of high-power dc supplies that employs Ine-commutated converters must evaluate the reactive power requirement because the compensation equipment represents a considerable portion of the total cost of the dc supply. By neglecting the commutation reactances and higher current harmonics, the power factor, PF, of the dc 
supply can be easily calculated to a first approximation for the module by-pass switching scheme.

The general formula for calculating the power factor of a dc supply that consists of $n$ modules connected in series, of which $q$ are not by-passed, is

$$
P F=\frac{\lambda+\frac{v_{q}}{v_{1}} \cos \alpha_{q}}{\left(\lambda^{2}+\left(\frac{v_{q}}{v_{1}}\right)^{2}+2 \lambda \frac{v_{q}}{v_{1}} \cos \alpha_{q}\right)^{1 / 2}}
$$

with the expression for $\lambda$ given by

$$
\lambda=1+\frac{v_{2}}{v_{1}}+\frac{v_{3}}{v_{1}}+\ldots \ldots+\frac{v_{q}}{v_{1}}-1
$$

Equation $(F-28)$ is valid in the voltage range

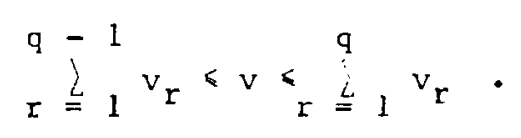

Equation(F-28)takes into account that in the module by-pass switching schem all but one of the nonshunted modules operate at a phase angle of $0^{\circ}$ where the remaining nonshunted module operates with the necessary delay angle to provide the desired output voltage.

The power factor of a dc supply with three series-connected modules, $\mathbf{n}=3$ and $\varepsilon=4$, is calculated in the following example. If the converter is designed according to the optimum switching procedure, the three voltages are given according to Eqs. $(F-6)(F-2 l)$, and $(F-22)$ to be $v_{1}=0.3968, v_{2}=0.2332$, and $v_{3}=0.37$. In the voltage range $0<v<v_{1}$, the power factor of the total converter is equal to the power factor of module 1 , that is

$$
P F=\cos \alpha_{1}
$$


with $\alpha_{1}$ being the phase-delay angle of module 1 , which varies from $0^{\circ}$ to $90^{\circ}$. Modules 2 and 3 are shunted and do not contribute to the overall power factor under the assumptions made. In the voltage range $v_{1} \leqslant v<v_{1}+v_{2}$, module 1 runs with a power factor equal to 1 and module 2 runs with a variable power factor. The overall power factor is

$$
\mathrm{PF}=\frac{1+\frac{\mathrm{v}_{2}}{\mathrm{v}_{1}} \cos \alpha_{2}}{\left(1+\left(\frac{\mathrm{v}_{2}}{\mathrm{v}_{1}}\right)^{2}+2 \frac{\mathrm{v}_{2}}{\mathrm{v}_{1}} \cos \alpha_{2}\right)^{1 / 2}}
$$

with the delay angle of module $2, \sigma_{2}$, varying $i$ rom $0^{\circ}$ to $90^{\circ}$. In the voltage range $\left(v_{1}+v_{2}\right)<v<1$, modules 1 and 2 have a power factor equal to unity; and module 3 has a variable power factor that depends on its phase-delay angle $\alpha_{3}$. The resultant power factor of the dc supply is

$$
P F=\frac{1+\frac{v_{2}}{v_{1}}+\frac{v_{3}}{v_{1}} \cos \alpha^{3}}{\left(\left(1+\frac{v_{2}}{v_{1}}\right)^{2}+\left(\frac{v_{3}}{v_{1}}\right)^{2}+2\left(1+\frac{v_{2}}{v_{1}}\right)\left(\frac{v_{3}}{v_{1}}\right) \cos c_{3}\right)^{1 / 2}} .
$$

Figure F-4 shows, for the chosen example, the power factor of the dc supply as a function of the dc output voltage. The dashed line in the same figure indicates the power factor of a one-module supply. The power factor for a two-module supply, designed with optimum voltage rating, is also included in Fig. F-4.

\section{Conclusion}

The results for the voltage rating of the converter modules obtained from the optimfiation procedure may be used as a guideline for an actual design. Engineering considerations such as equal voltage rating of each module, standardization, compromise between number of modules and added switching complexity, reactive-power consumption, actual blocking voltage, and forward-current rating of thyristors have to be weighed to obtain an 
acceptable overall engineering design. It is worth mentioning that the voltage rating of the first module, as obtained from the derivation, can be split into several modules with identical current and voltage ratings if the overall voltage rating of the dc supply requires series connections of thyristors. The module by-pass switching scheme is especially suitable for applications where the amplitude of the converter output voltage requires thyristors or converter modules connected in series. In very low-voltage high-current dc supplies, a parallel connection of modules, each having different voltage and current ratings, would be theoretically advantageous. This scheme has been suggested in Ref. 3. However, to obtaln current sharing between modules designed for different peak voltages, excessively large inductive interphase reactors would be required to guarantee uninterrupted bridge currents and current sharing. The optimization procedure as outlined above is equally relevant for parallel- and series-connected converter modules because it is derived on a per-unit basis.

\section{SERIES-PARALLEL MODULE SWITCHING}

\section{A. Switching Circuit}

To meet the requirement of high-voltage, low-current and low-voltage, high-current output of a constant power dc supply, a series-parallel moduleswitching scheme appears to result in the lowest converter rating. Consider two identical converter modules with a current and voltage rating of $0.5 \mathrm{pu}$. In the voltage range $0 \leqslant \mathrm{v} \leqslant 0.5 \mathrm{pu}$, the two modules are connected in parallel. Current sharing is accomplished by making the output voltage of the two modules identical. In the range $0.5 \leqslant v \leqslant 1 \mathrm{pu}$, the modules are connected in series. The transition from series to parallel connection must occur without interruption of the load current and line power.

A circuit that allows module switching is shown in Fig. F-5. The clrcult is designed to minimize transients by opening and closing switches only in the currentless state. The transition from the series connection of the modules to the parallel connection takes place in the following sequence for positive converter voltages. The module current, $I_{2}$, which is identical to the load current, $I_{L}$, for the series connection, must be reduced to zero. This is accomplished by commutating the load current from module 2 into the by-pass thyristor. In a line-commutated converter, the commutation of the converter 
current into a diode or thyristor connected across the converter output is readily accomplished by phase-angle control. When the firing angle in an ideal converter with zero commutation reactance is delayed more than $120^{\circ}$ with respect to the natural point of commutation, the converter output voltage is negative at any time during a cycle, while the by-pass thyristor is forward biased and, when gated, can carry the load current. For a real converter with a commutation reactance, the delay angle has to be higher than $120^{\circ}$ for complete negative output voltage. Now switch 1, which is currentless, can be opened; and switch 2 can be closed to establish the parallel connection. The commutation of the load current from the by-pass thyristor into module 2 is again accomplished by phase-angle control. By reducing the phase angle from $\alpha=120^{\circ}$ to $\alpha=60^{\circ}$, the current commutation is accomplished. Equal-current sharing in the parallel-connected modules requires equal-phase delay angles in both modules and a small reactor to eliminate circulating currents.

The parallel-serles switching procedure functions in a similar way. If the load current is reduced to less than $0.5 \mathrm{pu}$, switching will occur. Half the load current flowing through module 2 will be commutated into module 1 by increasing the voltage, $V_{1}$, of converter 1 by a small amount, which is sufficlent to reverse bias the thyristors in module 2. Currentless switch 2 can be opened and switch 1 closed. Instantaneous positive output voltage of converter 2 commutates the load current from the by-pass thyristor into converter 2. To avold losses in the by-pass thyristor during the parallel mode of operation, a mechanical switch can be placed in parallel to the thyristor.

The switching scheme can function in a two-quadrant mode for positive and negative voltages, as is often required for dc supplies feeding large superconducting magnets. If, during the inverter mode of operation, parallel-to-series module switching should occur, voltage control of module 2 reduces $I_{2}$ to zero by making $V_{2}$ more negative than $V_{1}$. The switching of switch 1 and switch 2 then occurs. Current commutation from the by-pass thyristor to the module 2 requires reverse biasing of the by-pass thyristor $\left(\alpha_{2}<60^{\circ}\right)$. Figure $F-6$ shows, for $E=4$ in a power diagram, the operating conditions for voltage and current of the two modules for the two-quadrant mode of operation. The voltage relationships for the series-connection mode are given for the buck-boost operation to reduce the reactive power requirement. 


\section{B. Reactive-Power Requirement}

For an overall power supply system deslgn, the reactive-power requirement of the supply must be determined. By neglecting the commutating reactances, the reactive-power requirement can be easily calculated. For equal voltages of both converter modules, that $1 s, v_{1}=v_{2}$ over the full-current range (no buck and boost operation in the range $0<v<0.5)$, the power factor is identical to $\cos \alpha$ for the module series and parallel operating mode. Figure F-7 shows the power factor as a function of current. With buck and boost operation, the power factor can be improved in the series module connection as shown by the dashed curve in Fig. F-7. Module 1 has a unity power factor and module 2 a variable power factor, which results in an overall fower factor of

$$
\mathrm{PF}=\frac{1+\mathrm{v}_{2} \cos \alpha_{2}}{\left(1+\left(\frac{\mathrm{v}_{2}}{\mathrm{v}_{1}}\right)^{2}+2 \frac{\mathrm{v}_{2}}{\mathrm{v}_{1}} \cos \alpha_{2}\right)^{1 / 2}}
$$

The buck and boost operation results in the same power factor as the module by-pass switching scheme. See Eq. $\mid F-32)$ Comparison of the reactive-power requirement of the series-parallel switching circuit to the module by-pass scheme indicates that the module by-pass scheme for $n>3$ shows the lower reactive-power requirement.

\section{Conclusion}

The circuitry of the series-parallel switching scheme for two converter modules is not complicated. The added switching components and logic circuits are less expensive than the additional installed converter costs. A logical extension of the switching scheme with two modules would be a switching arrangement with more than two modules. However, the author is of the opinion that the switching complexity even of four modules, which would allow three combinations of module arrangements--four modules in series, four modules in 
parajle1, two modules in parallel with two in series--outweighs the reduced converter rating.

The switching time for a transition from a module arrangement to the other is $\sim 100$ to $150 \mathrm{~ms}$. This time is the sum of the switching times of the two disconnect switches in the circuit and the times to commutate the current into and out of the by-pass thyristor.

IV. INSTALLED CONVERTER POWER--COMPARISON OF THE TWO CIRCUITS

The installed converter power and, therefore, the converter cost depend on the current to voltage ratio $\varepsilon$. A converter designed for $V_{\max }$ and $I_{\max }$ has an installed converter power of

$$
P_{c}=E
$$

A converter designed according to the module by-pass scheme has an installed converter power approaching, for an infinite number of modules, the value given in Eq. $(\mathrm{F}-26)$.

A converter designed according to the parallel-series bridge switching scheme has a power rating of

$$
P_{c}=0.5 \varepsilon
$$

In the range $0<\varepsilon<0.25$, and

$$
P_{c}=2
$$

in the range $0.25 \leqslant \epsilon \leqslant 0.5$. The module switching arrangement would serve no useful purpose in the range $0.5<\varepsilon<1$.

Figure F-8 shows the installed converter power as a function of $\varepsilon^{-1}$ for four different converter schemes. For a fixed $\$ / \mathrm{kW}$ value for converter power cost, the curves are also proportional to the converter cost. The figure does not include the cost for the switching or by-pass mechanisms, which appear to be roughly the same for two modules in the serles-parallel switching 
arrangement and for three modules in the by-pass switching arrangement. A comparison of curves 3 and 4 with curve 1 shows that both schemes reduce the installed coverter power. Figure F-8 clearly points out a range, $0.2 \leqslant \varepsilon^{-1} \leqslant 0.4$, in which series-parallel module switching is more economical than bridge by-pass switching.

Additional overall system cost reductions can be achieved by incorporating both schemes into the design of high-power converters. DC supplies with ratings in the hundreds-of-megawatt range require a modularized design. From the advantages and limitations of both schemes, it appears that in an optimum design the total power supply should be subdivided into two main modules arranged according to the series-parallel switching scheme. Each main module consists of several, for instance, three, series-connected submodules, each having a by-pass switch. Such an arrangement shows reduced installed converter power and reactive power requirement.

\section{SUMMARY}

Many technological processes require high-power dc supplies with constant output power over a wide current and voltage range. Line-commutated converters with thyristors as switching elements are generally used for these applications. The very limited overload characteristic of thyristors requires the designer to size the converter according to both the maximum voltage and the maximum current, although in a constant-power mode these two parameters do not occur simultaneously. This results in an over-designed supply if other measures are not taken.

The design of dc power supplies with constant output power gives rise to special converter circuitry that keeps the installed converter power and, therefore, the converter cost at a minimum. Two converter circuits for this mode of operation were presented and analyzed.

The module by-pass circuit uses a series connection of converter modules, each designed for a different voltage and current rating. Each module can be by-passed when the module rating is exceeded to adjust for the constant output power over the full current-voltage range. An optimization procedure has been developed to determine the current and voltage rating of the converter modules for the lowest installed converter power. These current and voltage ratings should be used as guidelines in an actual design and, to obtaln an overall optimal design, they must be weighed against such engineering considerations 
as standardization, compromise between number of converter modules and switching complexity, and influence of thyristor rating on the design.

The circuit for a novel series-parallel module switching system is also examined. This circuit allows two converter bridges to be switched from a series connection in the high-voltage, low-current mode to a parallel connection when low voltages and high currents are required. Switching occurs without load-current interruption in both rectifier and inverter mode of the dc supply. Switching complexity seems to forbid switching circuits for more than two modules.

For both circuits, an expression for the installed power of the dc supply has been derived with the ratio of maximum to minimum current or voltage as a parameter. The series-parallel, module-switching circuit results in lower installed converter power for a current ratio in the range of 2.5 to 5 . The reactive-power requirement for both circuits was determined. Less reactive power is required in both cases than for a single-module converter designed according to its maximum voltage and maximum current.

\section{REFERENCES}

1. N. Jaysinghani, "Current-Controlled D.C. Power Supply for Plasma Research," Brown Bover1 Review, 98-104 (February-March 1974).

2. K. H. Sueker, Robicon Corporation, Pittsburgh, PA, personal communication (1979).

3. R. W. Boom, Ed., "Wisconsin Superconductive Energy Storage Project," $\underline{1}$, App. II-C, Engineering Experiment Station, College of Engineering, University of Wisconsin, Madison, WI, (1974). 


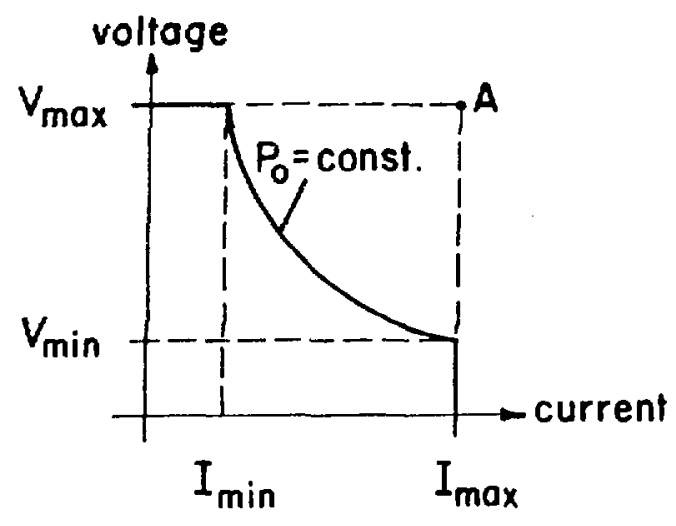

Fig. F-1. Current and voltage relationship for constant power converter output.

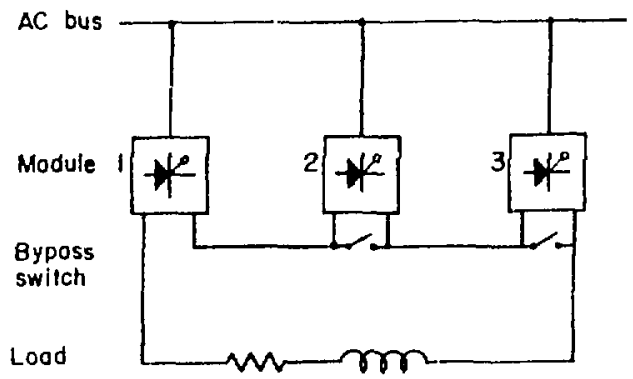

Fig. F-2. Module by-pass switching circuit.

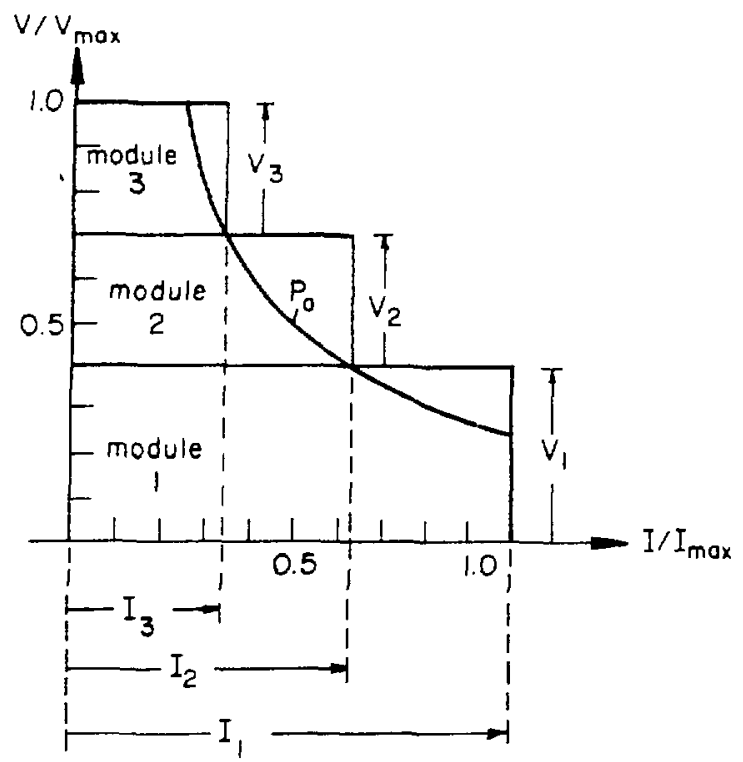

Eig. F-3. Current and voltage rating of individual modules in module by-pass switching circuit where $n=3$.

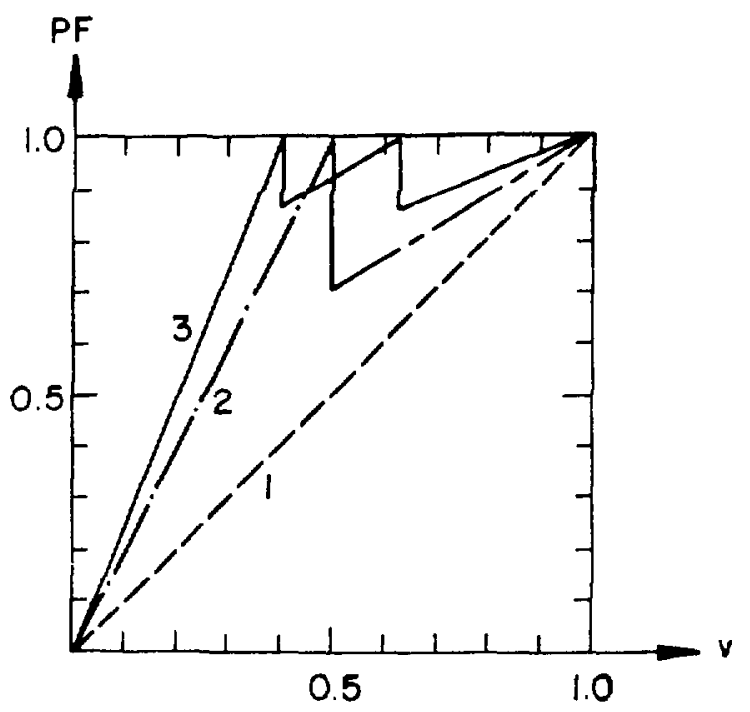

Fig. F-4. Power factors of module bypass switching circuit with 1, 2, and 3 modules in series.

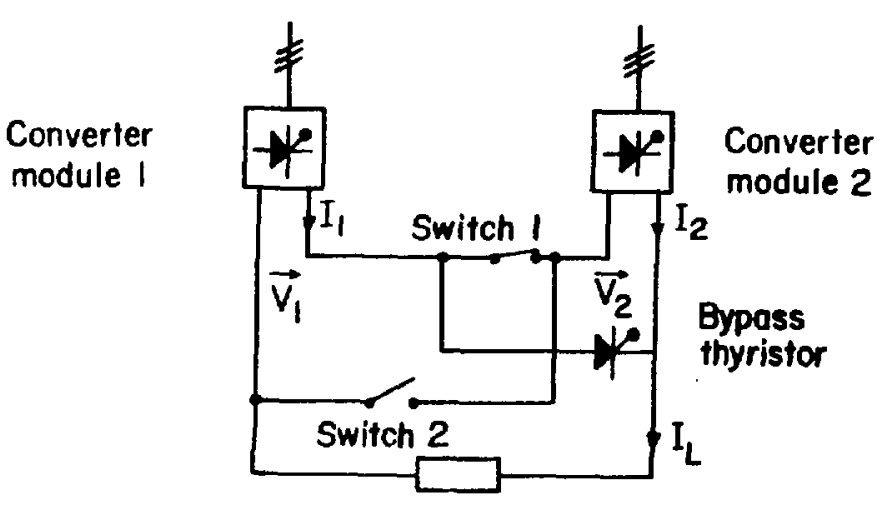

Fig. F-5. Series-parallel moduleswitching circuit. 


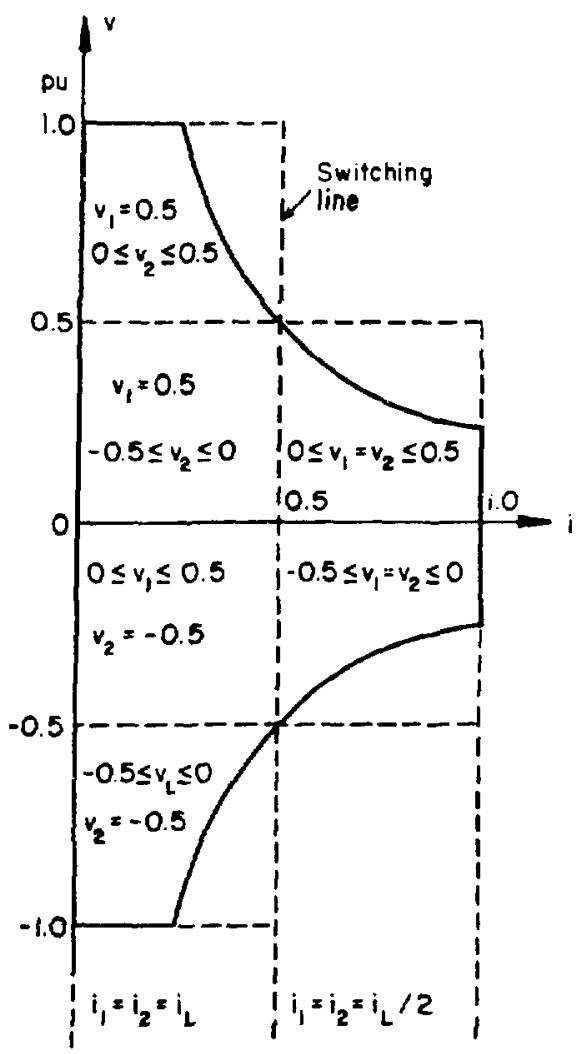

Fig. F-6. Operating mode of individual modules in the series-parallel module-switching circuit.

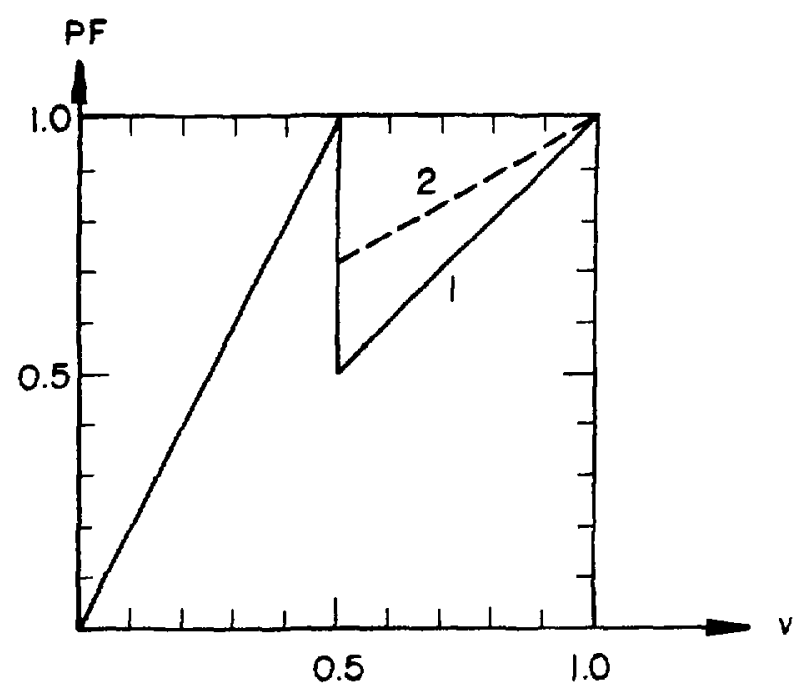

Fig. F-7. Power factors for seriesparallel module-switching circuit, with (2) and without (1) buck and boost operation.

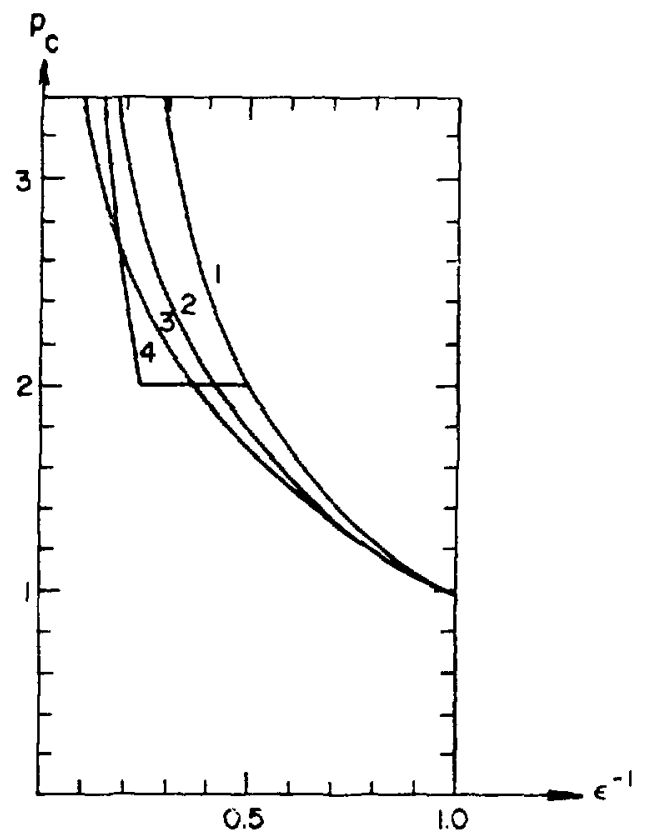

Fig. F-8. Installed, per-unit converter power ratio $\varepsilon^{-1}$ for different circuits: 1 , converter designed for $I_{\max }$ and $\mathrm{V}_{\max } ; 2$, module by-pass switching with $\mathrm{n}=3 ; 3$, module by-pass switching with $\mathrm{n}=\infty$; and 4 , series-paralle? module-switching. 